\title{
THE INFLUENCE OF PRE-TREATMENT BY PRIMING ON THE CMY REPRODUCTION QUALITY PRINTED WITH ELECTROINK
}

\author{
Marko MORIĆ, Igor MAJNARIĆ, Klaudio PAP, Slaven MILOŠ
}

\begin{abstract}
In order to achieve high-quality colour prints by using an electrophotography printing machine, it is necessary to prepare the printing substrate. Additional treatment may be needed to achieve the better substrate surface tension for optimally attaching the liquid electrophotography ink to the fine art paper. To ensure good adhesion of the ink to the printing substrate, a pre-treatment by application of surface tension regulating fluids (priming) may be used. In this paper, we will determine the possibility of realization of the CMY prints and the possibility of achieving an increased range of tone value in electrophotography digital printing. Based on the results, the new possible values of reproduced CMY tones will be determined so that a higher print quality can be achieved. The application of primers changes the optical properties of the paper printing substrate, which directly affects the colour reproduction. An additional $100 \%$ increase of primer application will result in total colour changes of $\Delta \mathrm{E}_{\mathrm{C}}(0,5 \mathrm{~g} / \mathrm{m} 2 \& 1 \mathrm{~g} / \mathrm{m} 2)=0,06, \Delta \mathrm{E}_{\mathrm{M}}(0,5 \mathrm{~g} / \mathrm{m} 2 \& 1 \mathrm{~g} / \mathrm{m} 2)=0,42, \Delta \mathrm{E}_{\mathrm{Y}}(0,5 \mathrm{~g} / \mathrm{m} 2$ $\& 1 \mathrm{~g} / \mathrm{m} 2)=0,08$. In this scenario, $1 \mathrm{~g} / \mathrm{m}^{2}$ application of primer will produce the most intense full tones and therefore the highest quality prints for all three Electrolnk process colours.
\end{abstract}

Keywords: CIELab; colour difference; digital colour offset; Electrolnk; in-line primer; pre-treatment

\section{INTRODUCTION}

In order to achieve uniform and well-defined surface properties, it is necessary to treat the surface with certain substances. Most commonly these are acrylic polymers, vinyl ether polymers, polystyrene butadiene, polyesters, alkyd resins, phenolic resins, vulcanized thermoplastic elastomers, olefin thermoplastic elastomers, EVOH (ethyl vinyl alcohol copolymer) resins, polyvinyl chloride, resin oils, waxes [1]. Their application gives the possibility of achieving better mechanical properties of the materials, as well as their longterm use.

Depending on the aggregate condition of the printing media, the production speed and the thickness of the coating, different coating methods are applied - coating performed by pouring, direct immersion of the material in the coating, application through a narrow crack (extrusion), application with chamber squeegees, application by Mayer rod. All of these procedures are based on the principle of uniform application with $100 \%$ coverage of the surface. Differences between these techniques are evident in production productivity, which can range from 50 to $1.500 \mathrm{~m} / \mathrm{min}$ [2]. In order to achieve such production speeds, the viscosity of the coating fluid, whose value can vary from 10 to $20.000 \mathrm{mPa} \cdot \mathrm{s}$, is crucial. Thus, only ideal fluids (subject to Newton's laws) will achieve maximum coating productivity. The realized coating thicknesses can be different, depending on the coating techniques, ranging from 3 to $300 \mathrm{~g} / \mathrm{m}^{2}$ [3].

Coating techniques can also be applied to standard printing techniques such as flexographic printing, offset printing and contactless inkjet printing. The advantage of such coating technologies is the high productivity with the possibility of partial coating (due to the use of classic printing forms).

\section{THEORETICAL PART}

The in-line unit used with the HP Indigo WS 6800 series machines has two basic components. The coating is first charged with the substrate, followed by the application of a surface tension regulating fluid (primer). The printing substrate refining unit is used to apply a specific fluid that will affect the surface tension of the printing substrate and thus to the acceptance of ElectroInk [4]. Fig. 1 shows the design of the pre-treatment unit on HP Indigo printing machines.

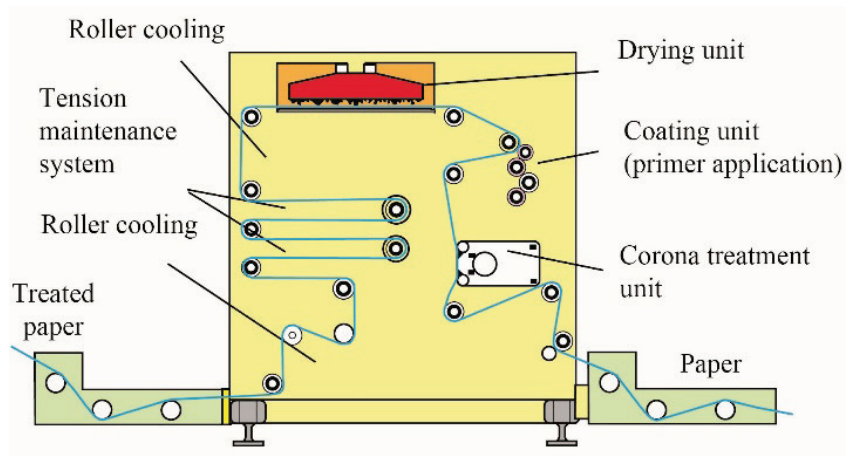

Figure $1 \mathrm{HP}$ Indigo unit for pre-treatment of printing substrates.

The printing substrate refining unit works by unwinding the roll with the printing pad and passing it through the corona unit. Therefore, the surface of the printing substrate is charged with ionized air in order to create a microstructure (roughness) that will improve the ink application on the printing substrate.

After that, the roll with the printing substrate enters a central coating unit containing five rollers. This results in a uniform application of the primer to the surface of the printing substrate. The amount of coating applied depends on the diameter of the primer coating roller, for example a coating thickness of $74 \mathrm{~mm}$ achieves a coating of $0,5 \mathrm{~g} / \mathrm{m}^{2}$, while a coating diameter of $84 \mathrm{~mm}$ achieves a coating of 1 $\mathrm{g} / \mathrm{m}^{2}$. In order for the primer to dry, the roll with the printing substrate must pass through a warm air drying tunnel and then reach the cooling rollers. Such printing substrate at the 
end of the refining unit enters the printing unit in HP Indigo where it is imprinted on a previously applied primer.

The priming unit, with the exception of the primer form roller, contains a pressure roller, a primer transfers roller, a distributor roller and a primer fountain roller (Fig. 2). The primer fountain roller is used to apply the ink from the ink tank, the distribution roller spreads the primer over the entire surface of the print, and the prime transfer roller connects them. The highest pressure roller presses the roller with the printing substrate in a controlled manner to form the highquality primer coating on the printing substrate. It is this construction that ensures uniform treatment and prints without any visible defects.

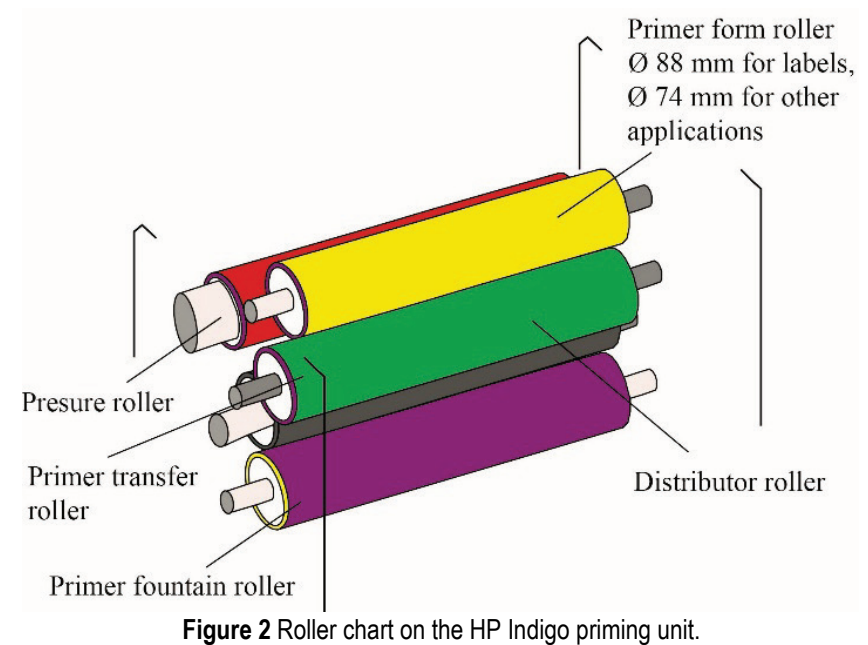

\subsection{Digital Colour Offset}

Digital colour offset is a specially developed electrophotography technique that utilizes the liquid ElectroInk. To generate a single imprint, the machine should contain a three cylinders' satellite unit (PIP cylinder, Intermediate cylinder and Impression cylinder), which serves for indirect transfer of ElectroInk to the printing substrate (Fig. 3).

ElectroInk is a special liquid electrophotography ink that, depending on the colour tone, contains the following components: volatile ISOPAR oil ( $90 \%$ to $95 \%$ ), pigment particles $(5 \%$ to $8 \%)$ and charge regulator - Image agent (1 $\%$ to $3 \%$ ). The liquid ink is prepared immediately prior to printing, using densitometers (the proportion of dry matter content in liquid) whose value is $1.70 \mathrm{~g} / \mathrm{cm}^{3}$ [5], [6]. The selective behaviour of ElectroInk depends on the established electrostatic field between the developer roller and the PIP cylinder or the PIP cylinder and the Intermediate Transfer Drum [7], [8].

The Liquid ElectroInk is transferred to the heated surface of the Intermediate Transfer Drum which has a soft offset rubber on its surface. During that process, ElectroInk changes its aggregate state and turns into a sticky paste [9]. In order to achieve a complete transfer, the offset rubber cover must meet two basic properties: a) it must be conducive; b) it must be heated to a temperature above $100^{\circ}[10]$.

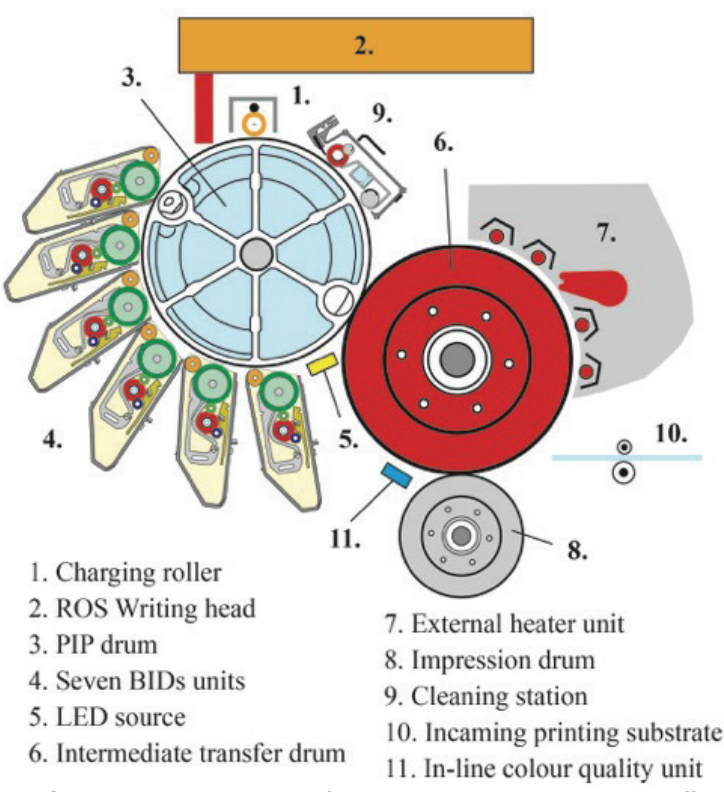

Figure 3 Schematic representation of printing process on digital colour offset (HP Indigo WS 6800 machine).

In order to ensure the ability to print in photo quality, BIDs should be added consist CMY colours. A parameter that significantly influences the quality is the adequate print of raster elements that can be directly controlled by activating laser power and by adjusting the colour transfer by changing the voltage on BID units and by selecting the appropriate printing substrate [11], [12], [13].

\section{EXPERIMENTAL PART}

For experimental printing, an HP Indigo WS 6800 was used with an integrated in-line primer injector and a corona unit [14]. The RIP (Raster Image Processor) used for separation of colour extracts was the ESCO HPE ProLiant ML350, while using a standard calibration curve LUT 0.5 and 180 lpi raster lines. For testing, the standard print form "FOGRA Image Quality" of the SRA3 dimension was used, out of which we applied Cyan (C), Magenta (M) and Yellow (Y) Separation [15].

Table 1 Characteristics of used fine art paper. Paper features - Condat digital gloss RL

\begin{tabular}{|l|c|c|c|}
\hline \multicolumn{4}{|c|}{ Paper features - Condat digital gloss RL } \\
\hline Attribute & Unit of measure & Value & Tolerance \\
\hline Grammage & $\mathrm{g} / \mathrm{m}^{2}$ & 90 & $\pm 4 \%$ \\
\hline Thickness & $\mu \mathrm{m}$ & 70 & $\pm 4 \%$ \\
\hline Opacity & $\%$ & 89 & -2.0 \\
\hline Whiteness D65/10 & $\%$ & 118.7 & \pm 3 \\
\hline Gloss of paper & $\%$ & 70 & \pm 5 \\
\hline Smoothness by Bekk & $\mathrm{s}$ & 1400 & $\pm 30 \%$ \\
\hline
\end{tabular}

The paper substrate used for the experiment was $90 \mathrm{~g} / \mathrm{m}^{2}$ Condat digital gloss RL (gloss coated fine art paper). The composition of such paper contains: $50 \%$ virgin cellulose, $40 \%$ calcium carbonate, $4.5 \%$ water and $5.5 \%$ latex and sizing agents [16]. Other properties of used fine art paper are shown in Tab. 1.

During the printing process paper was treated by means of two different primer depositions (Michem ${ }^{\circledR}$ In-Line 
Primer 030 manufactured by Michelman) in an amount of 0.5 $\mathrm{g} / \mathrm{m}^{2}$ and $1 \mathrm{~g} / \mathrm{m}^{2}$ (power of corona was $0 \mathrm{~W}$ ). Michem ${ }^{\circledR} \mathrm{In}-$ Line Primer 030 is a special substance manufactured for the in-line coating of HP Indigo printing machines, series WS 6800. This primer improves the adhesion of ElectroInk and enables better transfer of colour to a low surface energy substrate [17]. The technical characteristics of this primer are shown in Tab. 2.

Table 2 Characteristics of Michem® In-Line Primer 030

\begin{tabular}{|c|c|}
\hline \multicolumn{2}{|c|}{ Technical characteristics of in-line primer } \\
\hline Characteristic & Value \\
\hline Appearance & White fluid \\
\hline $\mathrm{pH}$ & $8.0-10.0$ \\
\hline Viscosity (cps) & $<100$ \\
\hline Application Number & 1 \\
\hline Application rate & $60 \mathrm{rpm}$ \\
\hline Manufacturer & USA, Belgium, Singapore \\
\hline
\end{tabular}

Since the measurements were conducted in industrial conditions, a surface tension measurement method was applied in accordance with the norm ASTM D-2578, with the use of indicator fluids containing 2-ethoxyethanol \& formamide [18]. In this way, we have avoided a greater pause between examination and testing phases. DYNE test results of surface tension without primer and after priming is given in Tab. 3.

Table 3 Surface tension measured by the DYNE method according to ASTM D-

\begin{tabular}{|c|c|c|c|}
\hline $\begin{array}{c}\text { Position of } \\
\text { measure }\end{array}$ & $\begin{array}{c}\text { Primer } \\
\mathrm{g} / \mathrm{m}^{2}\end{array}$ & $\begin{array}{c}\text { Primer } \\
\mathrm{g} / \mathrm{m}^{2}\end{array}$ & $\begin{array}{c}\text { Primer } \\
\mathrm{g} / \mathrm{m}^{2}\end{array}$ \\
\hline 1 & 36 & 34 & 38 \\
\hline 2 & 36 & 34 & 38 \\
\hline 3 & 36 & 34 & 38 \\
\hline 4 & 36 & 34 & 38 \\
\hline 5 & 36 & 34 & 38 \\
\hline 6 & 36 & 34 & 38 \\
\hline 7 & 36 & 34 & 38 \\
\hline Average & $\mathbf{3 6}$ & $\mathbf{3 4}$ & $\mathbf{3 8}$ \\
\hline
\end{tabular}

Table 4 Climatic conditions in the production plant during the measurement

\begin{tabular}{|l|c|c|}
\hline \multicolumn{1}{|c|}{ Samples } & Temperature ${ }^{\circ} \mathrm{C}$ & Relative humidity $\%$ \\
\hline Paper - primer $0 \mathrm{~g} / \mathrm{m}^{2}$ & 24,2 & 49 \\
\hline Paper - primer $0,5 \mathrm{~g} / \mathrm{m}^{2}$ & 24,7 & 51 \\
\hline Paper - primer $1 \mathrm{~g} / \mathrm{m}^{2}$ & 24,9 & 52 \\
\hline Min. & 24,2 & 49 \\
\hline Max. & 24,9 & 52 \\
\hline Average & $\mathbf{2 4 , 6 0}$ & $\mathbf{5 0 , 6 7}$ \\
\hline
\end{tabular}

Characterization of the printing surface is possible by determining the surface tension. Due to the specificity of testing, a DYNE test with indicator fluids of 34 to $44 \mathrm{mN} / \mathrm{m}$ (DYNE/cm) was applied in the experiment. This method was chosen because of the precision of sample measurements taken immediately after the printing substrate was released from the machine. Room temperature and relative humidity are very important for this method. Tab. 4 shows the climatic conditions used in the measurement of surface tension of the treated materials.

To determine the CMY reproducibility, the 4-generation X-rite eXact [19] colorimeter and spectrophotometer was used, while the Personal IAS was used for visual analysis of magnified CMY raster elements on the print [20]. The obtained CIE $L^{*} a^{*} b^{*}$ and CIE LAB $\Delta E$ results were compared to each other with the Origin 8.0 software. During experimental printing, the different power values of the primer were used $\left(0 \mathrm{~g} / \mathrm{m}^{2}, 0,5 \mathrm{~g} / \mathrm{m}^{2}\right.$ and $\left.1 \mathrm{~g} / \mathrm{m}^{2}\right)$.

As a result, nine different samples were produced during the experimental printing, as shown in the chronological experiment (Fig. 4).

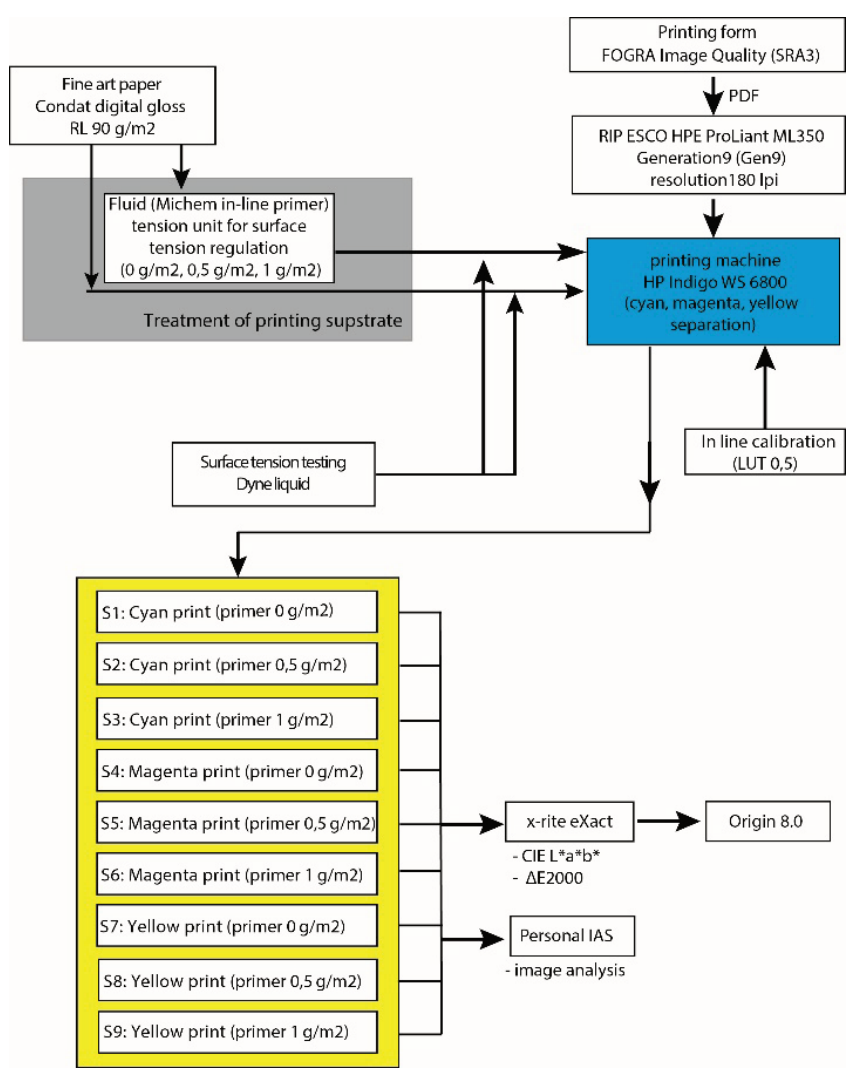

Figure 4 Schematic representation of the chronological experiment

\section{RESULTS AND DISCUSSION}

When printing on demanding printing substrates (characterized by low surface absorbency), it is necessary to treat the fluids that regulate the surface tension. The results are better bonding of ElectroInk as well as the optical properties of the printing substrate.

The colour change $\Delta E<1$ represents visually invisible colour changes, $\Delta E 1$ to 3 colour range is the standard, $\Delta E 3$ to 5 is the acceptable colour deviation range and $\Delta E>5$ is the unacceptable deviation area. Figs. 5, 6 and 7 show colour changes for process colours (cyan, magenta and yellow).

The reproduction curves created by applying a different amount of primer completely realize colour changes $(\Delta E)$, which is true for all experimental samples tested. This means that visible colour changes will be achieved by priming the printing substrate (paper) without applying the corona treatment. 

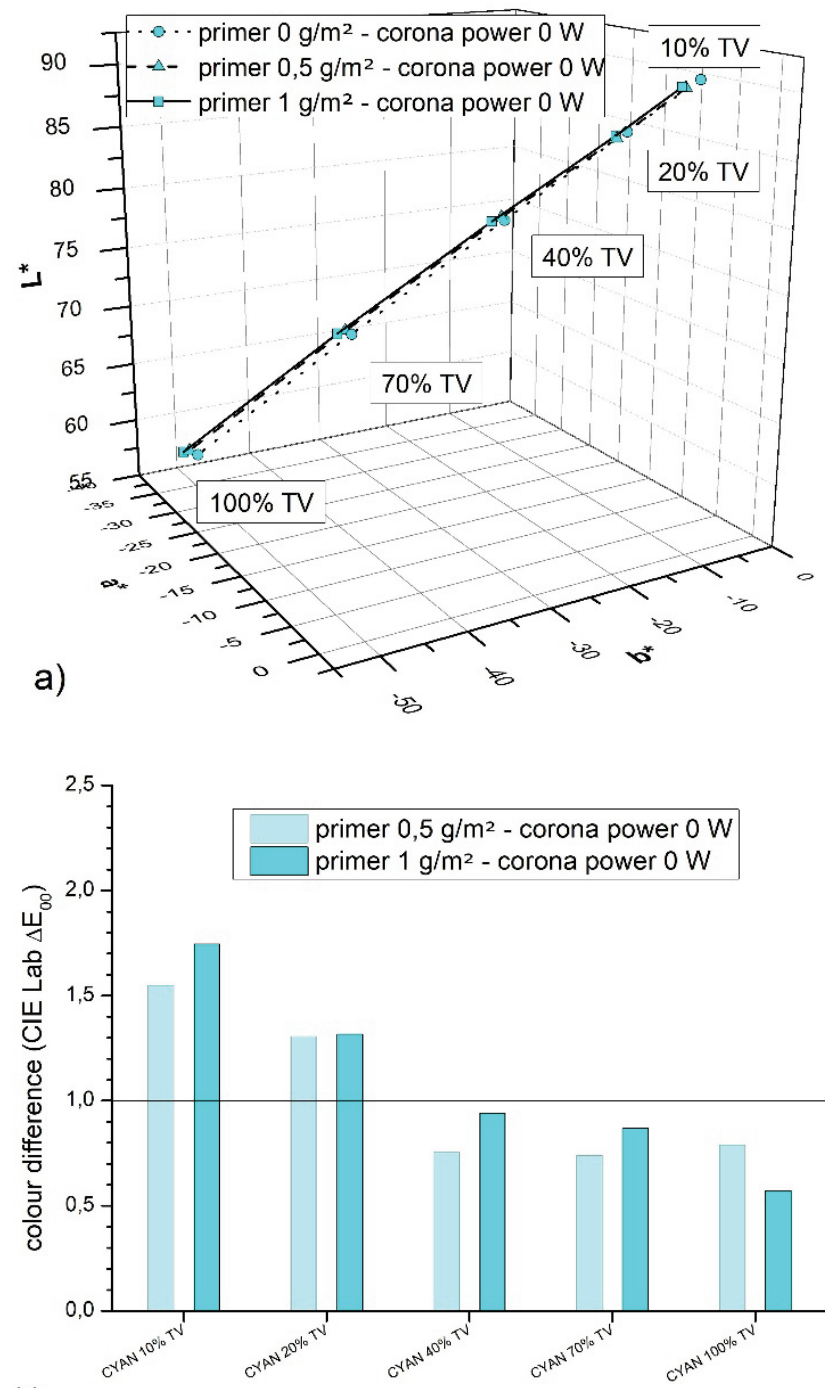

b)

ton value $(\%)$

Figure 5 Colour changes of cyan prints: a) the primer variation $\left(0 \mathrm{~g} / \mathrm{m}^{2}, 0.5 \mathrm{~g} / \mathrm{m}^{2}\right.$ and $1 \mathrm{~g} / \mathrm{m}^{2}$ ) without corona power ( $(0 \mathrm{~W})$; b) $\Delta E$ colour deviations

On untreated paper without activated corona treatment, greater colour changes will be achieved by applying a primer of $1 \mathrm{~g} / \mathrm{m}^{2}\left(\Delta E_{\text {avr.0w }}=1.09\right)$. In this case, the smallest surface coverage analysed will produce a larger colour change than full tone $\left(\Delta E_{\mathrm{C} 10 \%} 0 \mathrm{~W}=1.75 ; \Delta E_{\mathrm{C} 100 \%} 0 \mathrm{~W}=0.57\right)$. Imprints with a smaller amount of primer $\left(0.5 \mathrm{~g} / \mathrm{m}^{2}\right)$ produce less colour changes $\Delta E_{\mathrm{avr} .0 \mathrm{~W}}=1.03$. They are also expressed in the brighter areas $\left(\Delta E_{\mathrm{C} 10 \%}\right.$ ow $\left.=1.55\right)$ to stabilize with increasing surface coverage of the tone deviation $\left(\Delta E_{\mathrm{C} 100 \%}\right.$ $\mathrm{C} 70 \% 40 \%$ ow $=0.76)$. The application of a primer of $1 \mathrm{~g} / \mathrm{m}^{2}$ resulted in the deviation of cyan tones, which were expressed more in chromaticity ( $a^{*}$ and $b^{*}$ coordinates) and less in luminance $\left(L^{*}\right)$. By reducing the amount of primers, cyan prints become more unstable, meaning that in bright areas changes are more pronounced in chromaticity and in higher tones (from $40 \%$ to $100 \%$ of TV) in brightness. In order to achieve the most saturated cyan print, it is necessary to apply a primer in the amount of $1 \mathrm{~g} / \mathrm{m}^{2}$ without corona power $(0$ W).
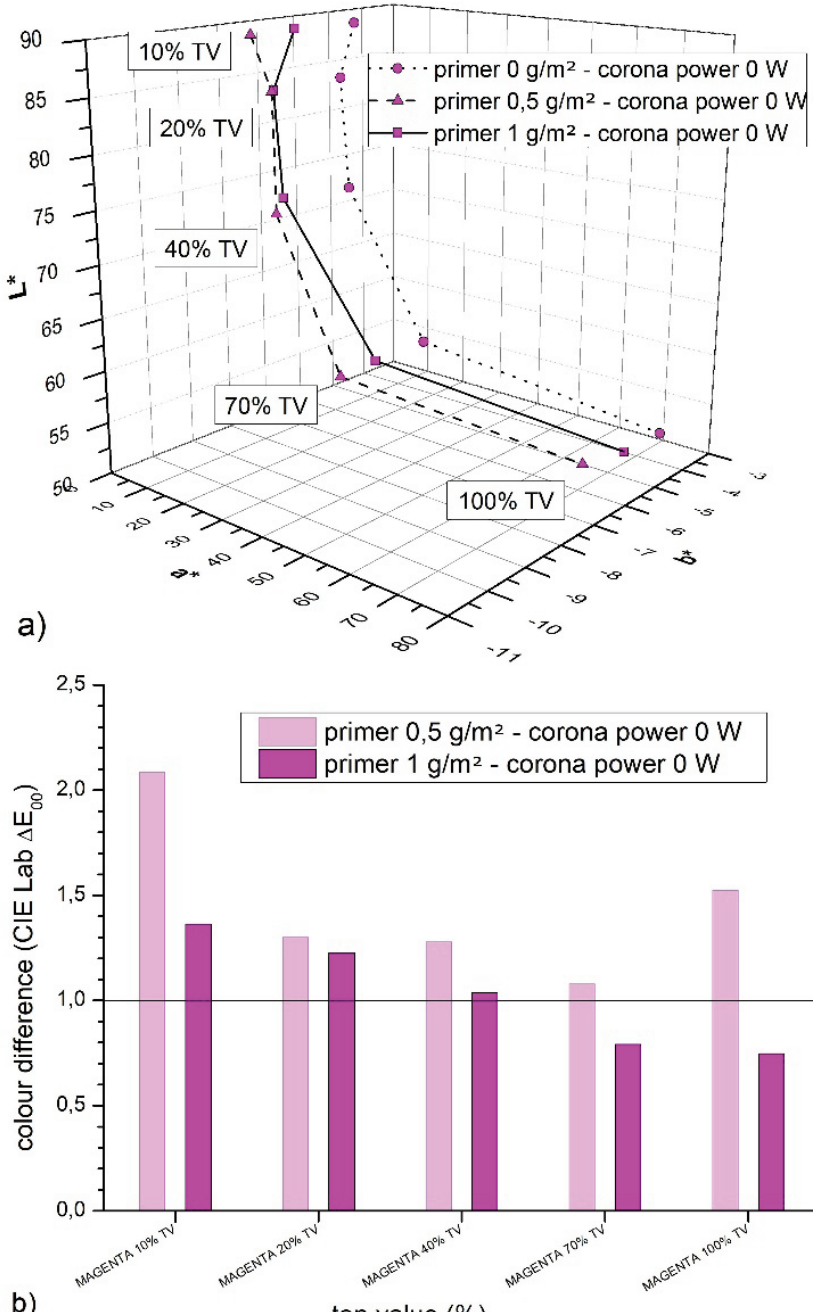

Figure 6 Colour changes of magenta prints: a) the primer variation $\left(0 \mathrm{~g} / \mathrm{m}^{2}, 0.5\right.$ $\mathrm{g} / \mathrm{m}^{2}$ and $1 \mathrm{~g} / \mathrm{m}^{2}$ ) without corona power ( $(\mathrm{W}) ;$ b) $\Delta E$ colour deviations

Magenta ElectroInk printing produces more pronounced colour changes in case of priming. Without activation of corona power and application of a primer of $0.5 \mathrm{~g} / \mathrm{m}^{2}$, a clear colour difference is achieved in all measurement fields $\left(\Delta E_{\text {avr.ow }}=1.45\right)$. Thus, two areas stand out with the values: $10 \%$ of TV $\left(\Delta E_{\mathrm{M} 10 \%}\right.$ ow $\left.=2.09\right)$ and $70 \%$ of TV $\left(\Delta E_{\mathrm{M} 10 \% \text { ow }}\right.$ $=1.08)$. With the further increase of primers, the print becomes more stable and achieves an average colour change of $\Delta E_{\mathrm{avr} .0 \mathrm{~W}}=1.03$. On such prints, larger surface coverage achieves a smaller colour change $\left(\Delta E_{\mathrm{M} 100 \% \_\mathrm{M} 70 \% \_0 \mathrm{w}}=0.76\right)$ and the smallest largest $\left(\Delta E_{\mathrm{M} 10 \%}\right.$ ow $\left.=1.36\right)$. By applying a fluid to refine the printing substrate, magenta experimental prints will retain a specific reproduction curve that changes up to $70 \%$ of TV in brightness and then sharply shifts to the coordinate $\left(a^{*}\right)$. However, priming without activating corona power produces the largest colour changes that are expressed along the chromaticity axes. The best full tone reproduction will be achieved in scenarios without corona treatment and with primer application $\left(1 \mathrm{~g} / \mathrm{m}^{2}\right)$. 


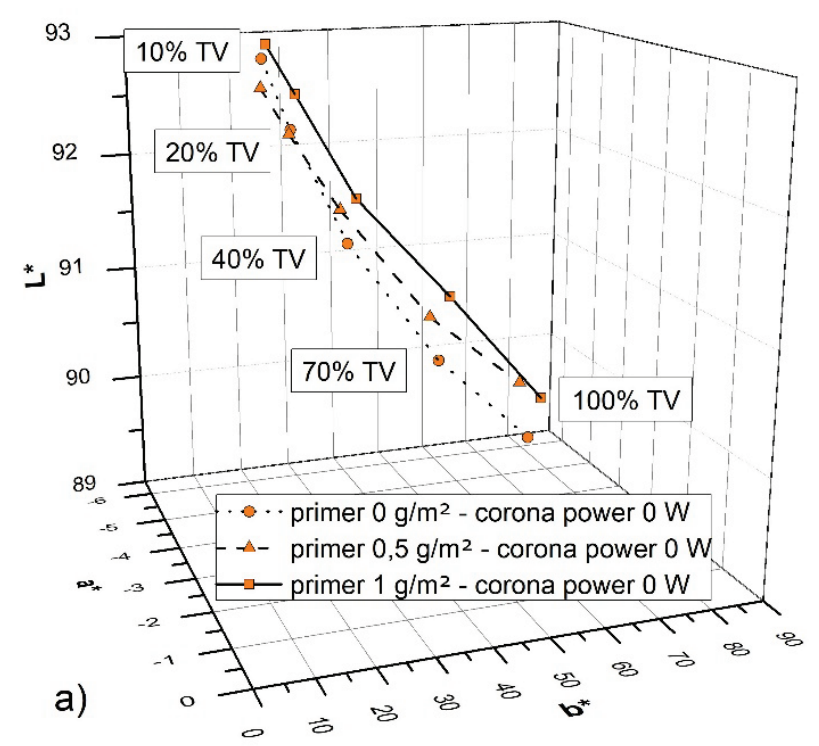

power. This is due to the chemical composition of the primer, which is not a colourless but light yellow colour. This is also the reason for such results.

In order to visualize realized $\triangle \mathrm{E}$ changes of $\mathrm{CMY}$ tones, experimental prints have been digitized and magnified 60 times (Fig. 8).

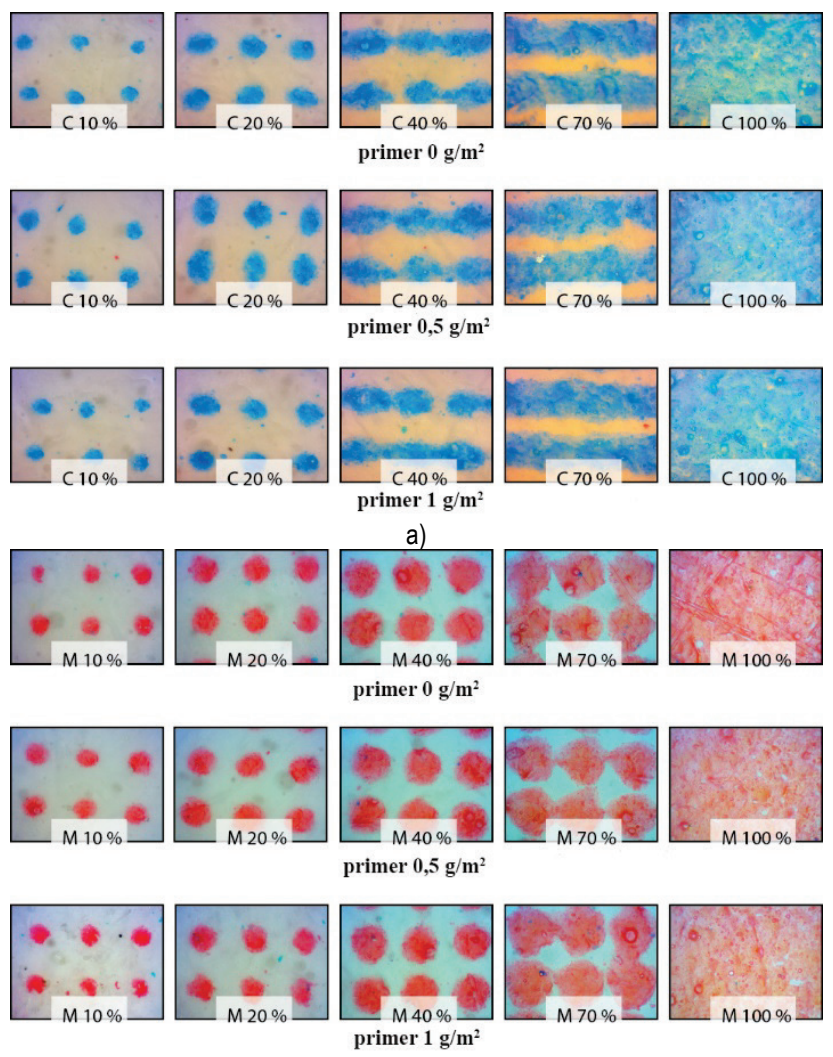

b)

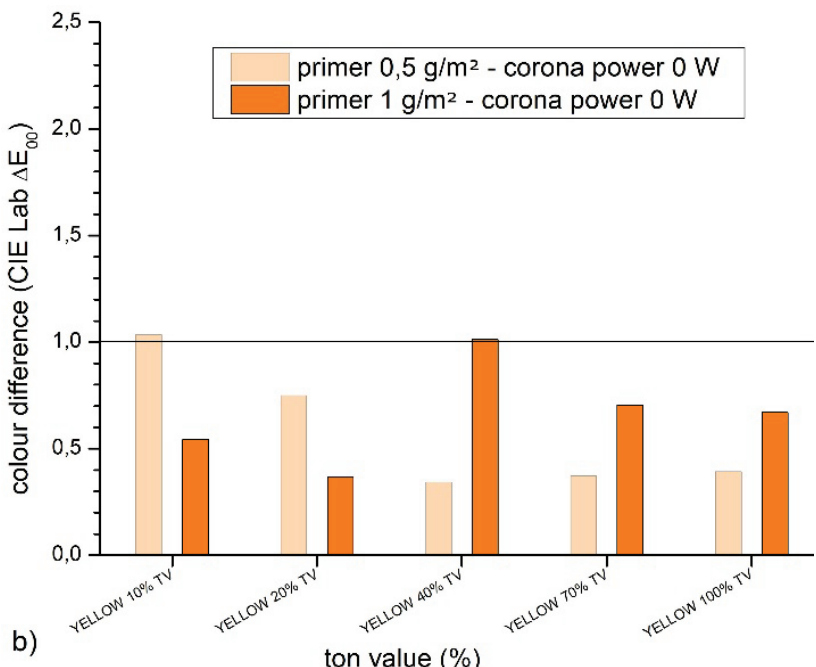

Figure 7 Colour changes of yellow prints: a) the primer variation $\left(0 \mathrm{~g} / \mathrm{m}^{2}, 0.5 \mathrm{~g} / \mathrm{m}^{2}\right.$ and $\left.1 \mathrm{~g} / \mathrm{m}^{2}\right)$ without corona power $\left.(0 \mathrm{~W}) ; \mathrm{b}\right) \Delta E$ colour deviations

Of all the analysed colour separations of yellow tones, by the priming process, it showed the least colour deviation and maximum uniformity of tones within the reproduction curve. Such prints, regardless of the applied corona power, will not produce larger colour changes than $\Delta E>1$. Experimental application of primer in the amount of $0.5 \mathrm{~g} / \mathrm{m}^{2}$ and without corona treatment will result in an average colour change of $\Delta E_{\text {avr. } 0 \mathrm{~W}}=0.58$. Higher priming $\left(1 \mathrm{~g} / \mathrm{m}^{2}\right)$ results in a slight increase in the average yellow colour deviations of $\Delta E_{\text {avr.0W }}=0.66$. The obtained results are characterized by a trend of realized tonal changes where a smaller amount of primers will produce larger deviations in the brighter parts of the image, while a larger amount of primers will produce larger deviations in the darker portions of the image. Only the primed yellow prints (Lab curve with no corona activated) produce a characteristic change that is evident in the rapid growth of chromaticity in the higher tone range. The most pronounced variable is $\left(+b^{*}\right)$. Thus, the best print will be realized with a coating of $1 \mathrm{~g} / \mathrm{m}^{2}$. The highest-quality yellow colour is created by priming $1 \mathrm{~g} / \mathrm{m}^{2}$ without activating corona
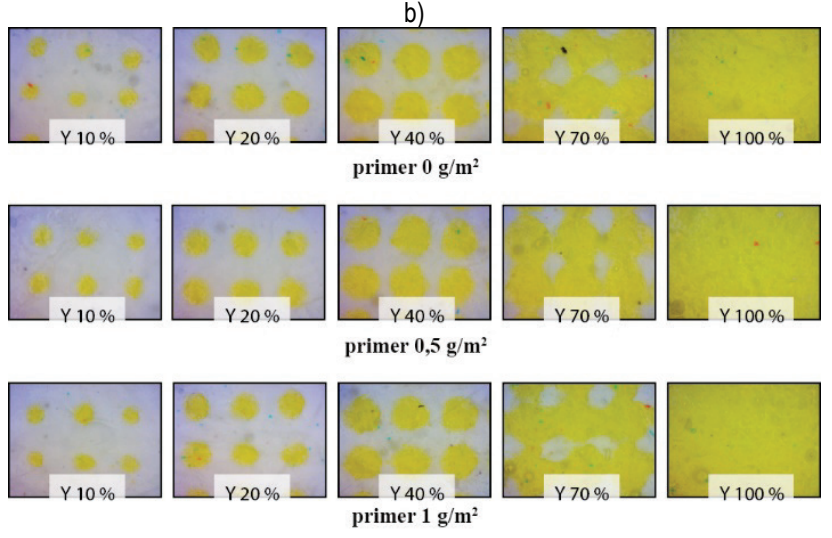

c)

Figure 8 Magnified HP Indigo prints by variations of priming $\left(0 \mathrm{~g} / \mathrm{m}^{2}, 0.5 \mathrm{~g} / \mathrm{m}^{2}\right.$ and $1 \mathrm{~g} / \mathrm{m}^{2}$ ) without corona power ( $\mathrm{W}$ ): a) cyan; b) magenta; c) yellow.

Cyan separation is characterized by the connection of raster print elements in the middle and higher tonal values. Such deformation is least visible in primed paper $\left(1 \mathrm{~g} / \mathrm{m}^{2}\right)$ which also gives the best print result. Magenta colour separation achieves the most correct raster elements if the printing substrate is primed also with a primer of $1 \mathrm{~g} / \mathrm{m}^{2}$. Such elements have geometric regularity and the highest print intensity (they have the highest optical density). The yellow separation is also best reproduced with a primer of 1 
$\mathrm{g} / \mathrm{m}^{2}$. With the good application of yellow ElectroInk quality, increase an additional yellowness printing substrate. Yellow prints are much better reproduced than other process separations.

\section{CONCLUSION}

The aim of this research was to define the effect of refinement of the printing substrate by the method of application of fluid to regulate the surface tension of the printing substrate. Thus treated print media for the purposes of the complete reproduction process require the redefinition of the qualitative properties of digital multicolour reproduction (CIE $L^{*} a^{*} b^{*}$, ton value, imbalance of print) when printing with ElectroInk.

The difference between the two colour changes in cyan prints, due to the variation of the primer $\left(0.5 \mathrm{~g} / \mathrm{m}^{2}\right.$ and 1 $\left.\mathrm{g} / \mathrm{m}^{2}\right)$, is $\Delta E$ difference $=0.06$. The difference in magenta prints is $\Delta E$ difference $=0.42$. Regarding the variation of the fluid for regulating the surface tension of the printing substrate, the difference between the two colour changes of the yellow prints is $\Delta E$ difference $=0.08$.

Thus, the best separation of elements is reproduced with cyan and yellow ElectroInk. The changes made by priming the printing substrate are not visible, but they are important in the whole process of calibrating the electrophotography printing machine. In combination with other parameters of the electrophotography printing process, those changes still affect the final colour results.

\section{REFERENCES}

[1] McLeod, D. M. (2006). Wire-Wound Rod Coating. In Coatings Technology Handbook, Third., A. A. Tracton, Ed. London: CRC Press - Taylor \& Francis Group, 18.1-18.7. https://doi.org/10.1201/9781420027327.pt2

[2] Bolanča, S., Majnarić, I., \& Golubović, K. (2015). Packaging Printing Today. Acta Graph. 236, 26(4), 27-33.

[3] Bolanča, S. (2013). Tisak ambalaže. Zagreb, Hrvatska: Hrvatska sveučilišna naklada.

[4] HP, Operating the Inline Primer. Available: ftp://ftp.hp.com/ pub/gsb/Indigo/Industrial/Software/CN-ILP_User_Guide/ CA394-11321.pdf. .

[5] Benzion, L. et al. (1988). Toner for Use in Compositions for Developing Latent Electrostatic Images, Method of Making the Same, and Liquid Composition Using the Improved toner. 4,794,651,

[6] Yaacov, A. (1991). Humidity Tolerant Charge Director Compositions, p. 6.

[7] Forgacs, P. \& Teishev, A. (2013). Electro-Rheological Model of HP Indigo ElectroInk. J. Imaging Sci. Technol., 56(4), 1-9. https://doi.org/10.2352/J.ImagingSci.Technol.2013.57.3.030403

[8] Majnaric, I., Golubovic, K., Bolanca, S., \& Modric, D. (2011). Voltage Effect on Developing Process and B\&W Reproduction, DAAAM Int. Sci. B. 2010. https://doi.org/10.2507/daaam.scibook.2010.45

[9] Majnarić, I., Bolanča, I., Bolanča, Z., \& Milković, M. (2005). Conditions in digital printing of packaging on the print quality. In International Conference on Digital Production Printing and Industrial Applications, DPP2005 - Final Program and Proceedings, vol. 2005.
[10] Gazit, A. (1998). Imaging Apparatus and Intermediate Transfer Blanket Therefor, p. 20.

[11] Majnaric, I., Modric, D., \& Golubovic, K. (2008). Influence of laser power output on the quality of colour imaging. In Annals of DAAAM and Proceedings of the International DAAAM Symposium.

[12] Majnaric, I., Bolanca, Z., \& Bolanca Mirkovic, I. (2009). The influence of the developer drum voltage on screen dot formation. In Annals of DAAAM and Proceedings of the International DAAAM Symposium.

[13] Majnarić, I., Hladnik, A., Muck, T., \& Bolanca Mirkovic, I. (2015). The influence of ink concentration and layer thickness on yellow colour reproduction in liquid electrophotography toner. Tehnicki vjesnik, 22(1), 145-150. https://doi.org/10.17559/TV-20140321230455

[14] Hp, T. et al. HP Indigo WS6800 Digital Press and packaging production.

[15] Kraushaar, A. (2018). Process Standard Digital Handbook Munich: Fogra Research Institute for Media Technologies.

[16] Lecta group (2018). Condat data sheet, Available: https://cmspro.lecta.com/Digital/LectaProductCertificates/Saf etyDataSheet_Condat.pdf.

[17] Sheet, T. D. (2018, April). Michem ${ }^{\circledR}$ In-Line Primer 030 Michem ${ }^{\circledR}$ In-Line Primer 030, 1-2.

[18] ASTM International, Standard Test Method for Wetting Tension of Polyethylene and Polypropylene Films.

[19] X-rite (2018). x-rite eXact Spectrophotometer, Available: https://www.xrite.com/categories/portablespectrophotometers/exact.

[20] QEA, Personal IAS. Available: http:/www.qea.com/upload/ files/products/datasheet_personalias-newaddr.pdf.

\section{Contact information:}

\section{Marko MORIĆ, PhD}

(Corresponding author)

University North, Multimedia, Design and Application, Jurja Križanića 31b, 42000 Varaždin, Croatia mmoric@unin.hr

Igor MAJNARIĆ, Assoc. Prof. University of Zagreb, Faculty of Graphic Arts, Getaldićeva 2, 10000 Zagreb, Croatia igor.majnaric@grf.hr

\section{Klaudio PAP, Prof.}

University of Zagreb, Faculty of Graphic Arts, Getaldićeva 2, 10000 Zagreb, Croatia

klaudio.pap@grf.hr

Slaven MILOŠ, MSc

Grafiknet Itd.

Odranska 1/1, 10000 Zagreb, Croatia

slaven.milos@grafiknet.hr 